\title{
AVALIAÇÃO DO TRANSPORTE DO ÁCIDO 2,4-DICLOROFENOXIACÉTICO ATRAVÉS DE UM LISÍMETRO
}

\author{
Daniel Macedo Neto, Sandro Froehner* e Karina Scurupa Machado \\ Departamento de Engenharia Ambiental, Universidade Federal do Paraná, Centro Politécnico, 81531-980 Curitiba - PR, Brasil
}

Recebido em 21/3/12; aceito em 12/6/12; publicado na web em 10/8/12

\begin{abstract}
ASSESSMENT OF TRANSPORT OF 2,4-DICHLOROPHENOXYACETIC ACID USING A LYSIMETER. The objective of this study was to evaluate the transport of one of the most toxic and best-selling herbicides in Brazil. The active ingredient 2,4-dichlorophenoxyacetic acid (2,4-D) was applied onto the surface of a tank-type lysimeter, filled with undisturbed soil, in Curitiba, Parana State. Samples of infiltration and runoff water were obtained during rain simulations. The concentrations of the active ingredient 2,4-D showed a rapid decrease in the environment, with mass losses of $29.12 \%$ by infiltration and $0.87 \%$ by runoff.
\end{abstract}

Keywords: lysimeter; transport; 2,4-dichlorophenoxiacetic acid.

\section{INTRODUÇÃO}

Os altos índices de produção agrícola atingidos no Brasil demandam o uso intenso de agrotóxicos de variadas composições químicas. Com constante abertura de novas fronteiras, a agricultura intensiva praticada no país vem batendo recordes de produção que, paralelamente, refletem num crescente volume de agrotóxicos comercializados em território brasileiro. ${ }^{1}$ Segundo estatísticas, o Brasil é o maior consumidor de agrotóxicos no mundo e o grupo dos herbicidas é o mais comercializado mundialmente. ${ }^{1,2}$ No Brasil, 127 mil toneladas desse grupo foram comercializadas em 2009, sendo os ingredientes ativos glifosato e ácido 2,4-diclorofenoxiacético (2,4-D) os mais comercializados oficialmente. ${ }^{3}$

Primeiro herbicida seletivo desenvolvido ainda nos anos 1940, o 2,4-D $\left(\mathrm{C}_{8} \mathrm{H}_{6} \mathrm{Cl}_{2} \mathrm{O}_{3}\right)$ é largamente utilizado para aplicação na pré- ou pós-emergência de plantas infestantes em cultivos de trigo, soja, milho, arroz, cana-de-açúcar e pastagens. ${ }^{3}$ As formulações na forma de sal são absorvidas pelo sistema radicular das plantas e aquelas na forma de éster são absorvidas pelas folhas. Em ambos os casos, o 2,4-D flui pelo xilema e floema das plantas. ${ }^{4}$

Atribui-se ao 2,4-D a classificação toxicológica máxima (Classe I) que, em animais, se refere à $\mathrm{DL}_{50}$ (dose letal que elimina $50 \%$ de uma população) por via oral entre $0-50 \mathrm{mg} \mathrm{kg}^{-1}$; por via dérmica entre $0-200 \mathrm{mg} \mathrm{kg}^{-1} ; \mathrm{CL}_{50}$ (concentração letal que elimina $50 \%$ de uma população) por via respiratória entre $0-0,2 \mathrm{mg} \mathrm{L}^{-1} \mathrm{e}$ irritação para pele e olhos classificada como severa. ${ }^{5,6}$ Em mamíferos o 2,4$\mathrm{D}$ pode atacar o fígado, o sistema nervoso central e o coração; no ser humano, uma inalação prolongada pode gerar efeitos agudos como tonturas, tosse, fraqueza e até perda temporária de coordenação muscular, ${ }^{4,6,7}$ já que os efeitos principais e mais recorrentes decorrem da manipulação inadequada do produto, que pode gerar irritação na pele e nos olhos. ${ }^{6}$

Quanto ao potencial de periculosidade ambiental (PPA), parâmetro que leva em consideração bioacumulação, persistência, transporte, toxicidade e os potenciais mutagênico, teratogênico e carcinogênico, o 2,4-D é considerado perigoso ${ }^{3}$ (Classe III), numa classificação que vai de I (máximo PPA) a IV (mínimo PPA). Apresenta tempo de meia-vida de 4,6 a 17,2 dias no solo e de 4,5 a 7 dias na água, ${ }^{8}$ solubilidade em água de $23,18 \mathrm{~g} \mathrm{~L}^{-19} \mathrm{e} \mathrm{pK}_{\mathrm{a}}=2,6 .{ }^{7,10}$ É avaliado como altamente transportável e muito tóxico para organismos aquáticos. É pouco tóxico para organismos do solo, aves e abelhas. ${ }^{3,7}$

*e-mail: froehner@ufpr.br
Processos de transporte como a infiltração e o escoamento superficial, principalmente se induzidos por chuvas que ocorrem logo após a aplicação de agrotóxicos, podem acarretar em riscos de contaminação de águas superficiais e subterrâneas. ${ }^{11}$ Devido às dificuldades de avaliação do transporte de pesticidas, os lisímetros podem ser uma alternativa para entendimento desse transporte no ambiente. ${ }^{12}$ Lisímetros do tipo tanque são estruturas que isolam um volume de solo entre a superfície e certa profundidade, permitindo o seu uso em estudos hidrológicos, geoquímicos e ecológicos. ${ }^{12} \mathrm{O}$ comportamento de alguns ingredientes ativos usados como agrotóxicos já foi investigado utilizando lisímetros em diversos tipos de solos e regiões brasileiras..$^{2,13-15}$ No entanto, o comportamento ambiental é muito dependente do tipo de solo em que o agrotóxico foi aplicado, sendo isso fator determinante para avaliação do transporte e destino. ${ }^{11}$ Este trabalho teve como objetivo avaliar o transporte do ingrediente ativo 2,4-D por infiltração e escoamento superficial induzidos pela simulação de chuvas sobre lisímetro gravimétrico.

\section{PARTE EXPERIMENTAL}

\section{Experimento em lisímetro}

O lisímetro utilizado está localizado na cidade de Curitiba, no campus Centro Politécnico da Universidade Federal do Paraná, no ponto de coordenadas $25^{\circ} 26^{\prime} 53^{\prime \prime}$ de latitude Sul e $49^{\circ} 13^{\prime} 52^{\prime \prime}$ de longitude Oeste (UTM 677.848 L 7.184.231 S). Foi construído em julho de 2009 e encontra-se instalado na altitude aproximada de 925 m em solo estruturado (não deformado), classificado como Latossolo Vermelho Amarelo, de textura argilosa a média. ${ }^{16}$ Segundo a classificação de Köppen, o clima é o Cfb, subtropical úmido, mesotérmico, com verões frescos, geadas frequentes no inverno, sem estação seca, com temperatura média do mês mais quente inferior a $22^{\circ} \mathrm{C}$ e do mês mais frio inferior a $18{ }^{\circ} \mathrm{C}$. A precipitação média no local é de 1.400 a $1.600 \mathrm{~mm} \mathrm{ano}^{-1} .{ }^{17}$

A composição granulométrica do solo do lisímetro foi determinada pelo método da pipeta, ${ }^{18}$ resultando em $38 \%$ para silte e $31 \%$ para argila, o que configura uma textura média ao longo do perfil. O teor de carbono orgânico, obtido pelo método de Walkley Black, ${ }^{19,20}$ foi de $1,15 \%$. A capacidade de troca catiônica (CTC) de $23,27 \mathrm{cmol} \mathrm{L}^{-1}$ e o $\mathrm{pH}=4,0$ foram obtidos segundo metodologia da Embrapa. ${ }^{18}$

O lisímetro gravimétrico utilizado possui área de $1 \mathrm{~m}^{2}$, paredes em acrílico com $10 \mathrm{~mm}$ de espessura, volume de solo indeformado de $1 \mathrm{~m}^{3}$. A superfície encontra-se na horizontal e possui delimitação 
nas laterais por uma pequena mureta, que impede o escoamento superficial do entorno para dentro do tanque e do tanque para fora. $\mathrm{O}$ fechamento lateral do tanque impede também ganhos ou perdas por escoamento subterrâneo horizontal. ${ }^{12}$ Sobre o lisímetro foi instalado um simulador de chuva composto por reservatórios de água, gerador, bomba e dispersor com aspecto de chuveiro de movimento pendular.

Quando da execução do experimento, a superfície do lisímetro encontrava-se coberta por gramíneas com sistema radicular de pequena penetração, que cobrem grande parte do campus. Não havia registros de aplicações prévias de herbicidas na área. O solo superficial foi parcialmente revolvido durante as simulações, para representar o manejo do solo para cultivo.

Sobre a área superficial do lisímetro foi aplicado o herbicida DMA $806 \mathrm{BR}^{\circledR}$, fabricado pela Dow Agrosciences Industrial, adaptado à concentração de $4,03 \mathrm{~g} \mathrm{~L}^{-1}$ (ou $200 \mathrm{~L} \mathrm{ha}^{-1}$ ). A aplicação do volume de $250 \mathrm{~mL}$ do herbicida foi cuidadosamente realizada no dia 08/07/10, em fim de tarde com solo úmido.

Na manhã seguinte, 15 h após a aplicação do herbicida, uma precipitação com intensidade de $45 \mathrm{~mm} \mathrm{~h}^{-1}$ foi simulada por 90 min sobre a superfície do lisímetro, gerando vazões de infiltração que foram amostradas a cada $10 \mathrm{~min}$. Foram coletadas 10 amostras com volume de $1 \mathrm{~L}$ cada, não havendo geração de escoamento superficial. Após $38 \mathrm{~h}$ da aplicação do herbicida à base de 2,4-D, uma nova precipitação com intensidade de $45 \mathrm{~mm}$ $\mathrm{h}^{-1}$ foi simulada por $60 \mathrm{~min}$ sobre a superfície do lisímetro. $\mathrm{O}$ mesmo procedimento amostral foi repetido, obtendo-se 7 amostras de água de infiltração; novamente não houve geração de escoamento superficial. Na $3^{\mathrm{a}}$ simulação, realizada 46 h após a aplicação do herbicida, o sistema de bombeamento da precipitação foi ajustado para gerar uma intensidade pluviométrica de $115 \mathrm{~mm} \mathrm{~h}^{-1}$, durante $75 \mathrm{~min}$. Essa mudança na configuração do experimento permitiu a obtenção de amostras tanto de infiltração como de escoamento superficial.

O tempo de enchimento das garrafas (com amostras) bem como o volume coletado ( $1 \mathrm{~L}$ por amostra) foram registrados visando aferir as vazões de escoamento superficial e de infiltração. As vazões foram calculadas pela razão entre o volume coletado e o tempo de enchimento de cada amostra. No período entre coletas, a água de infiltração e escoamento superficial era descartada.

\section{Determinação quantitativa do 2,4-D}

Seguiu-se o procedimento descrito na literatura para extração e quantificação do 2,4-D. ${ }^{21}$ Resumidamente, o procedimento de análise consistiu na filtração em papel filtro quantitativo, seguido de filtração em membrana de nitrato de celulose 0,45 $\mu \mathrm{m}$. Em seguida, passou-se à extração do ingrediente ativo em colunas de extração em fase sólida do tipo SPE C18, da marca Agilent, sendo utilizado $1 \mathrm{~L}$ de amostra. O composto ativo adsorvido na coluna foi eluído com metanol $(10 \mathrm{~mL})$; o solvente foi evaporado até à secura e o resíduo foi redissolvido em acetonitrila.

Para a análise cromatográfica foi utilizada a técnica de cromatografia em fase líquida de alta eficiência, sendo empregado um equipamento da marca Shimadzu ${ }^{\circledR}$, modelo Prominence LC20A, equipado com coluna C-18, $5 \mu \mathrm{m}$, de $25 \mathrm{~cm}$, da marca Thermo Scientific ${ }^{\circledR}$. O comprimento de onda de máxima absorção foi $230 \mathrm{~nm}$, utilizando-se como solventes acetonitrila e água ultrapura acidificada com ácido fosfórico a pH 3,0, compondo uma fase móvel de 65 e 35\%, respectivamente. A vazão de leitura empregada foi de $1,4 \mathrm{~mL} \mathrm{~min}^{-1}$ e para as condições utilizadas o tempo de retenção foi de cerca de 3,0 min.

A curva analítica foi obtida através de soluções padrão com concentrações de 2,0; 3,0; 4,0; 5,0 e 10,0 $\mathrm{mg} \mathrm{L}^{-1}$, gerando coeficiente de correlação $r=0,9809$. Testes de recuperação foram conduzidos gerando rendimentos de extração entre 80 e $110 \%$.

\section{RESULTADOS E DISCUSSÃO}

\section{Aferição de vazões}

O experimento realizado revelou, primeiramente, dificuldade em gerar escoamento superficial a partir de precipitações da ordem de 45 $\mathrm{mm} \mathrm{h}^{-1}$, mesmo com 90 min ininterruptos de precipitação. Somente na $3^{\mathrm{a}}$ simulação, quando o equipamento permitiu simular uma chuva de $115 \mathrm{~mm} \mathrm{~h}^{-1}$ durante $75 \mathrm{~min}$, é que o escoamento superficial foi gerado. A configuração do lisímetro com coletores distintos para água de infiltração e de escoamento superficial permitiu aferir as vazões a partir do registro do volume e do tempo de coleta de algumas amostras (Figura 1).

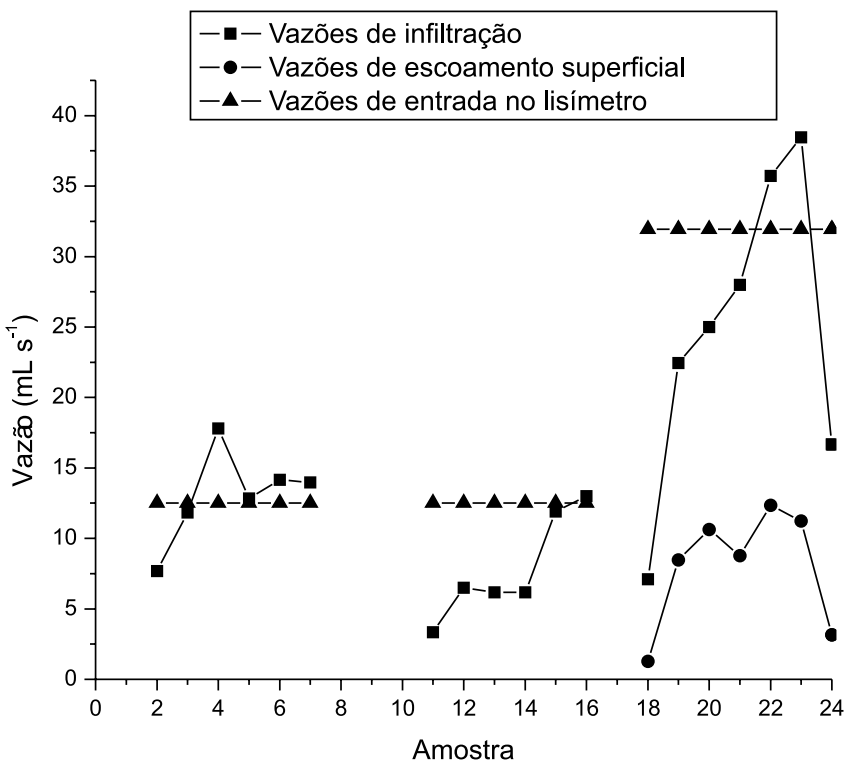

Figura 1. Vazões medidas durante as simulações: $1^{a}$ simulação - amostras 2 a 7; 2 $2^{a}$ simulação-amostras 11 a 16; $3^{a}$ simulação-amostras 18 a 24

$\mathrm{Na} 3^{\mathrm{a}}$ simulação, com uma precipitação de intensidade maior, foi possível ultrapassar a capacidade de infiltração do solo gerando escoamento superficial e podendo, assim, compará-lo às vazões de infiltração.

Considerando que o intervalo entre coletas de amostras foi de 10 min, pode-se considerar o eixo x como representante do tempo. Dessa forma pôde-se verificar comportamento crescente em termos de vazões até atingir um pico; a partir daí a curva apresenta comportamento decrescente. Isso pôde ser observado na $1^{\mathrm{a}}$ e $3^{\mathrm{a}}$ simulações, onde o número de amostras foi suficiente para registrar esse comportamento.

Outras constatações notórias foram a diminuição da magnitude dos picos da $1^{\mathrm{a}}$ para a $2^{\mathrm{a}}$ simulação, devido à condição de início do experimento em solo mais seco ( $1^{\mathrm{a}}$ simulação) e continuidade em solo mais úmido ( $2^{\mathrm{a}}$ simulação) e, a diferença entre as vazões de escoamento superficial e infiltração quando ambas foram geradas. Observou-se que a magnitude das vazões de escoamento superficial é bem menor que a de infiltração, e que, temporalmente, a infiltração precedeu o escoamento superficial em 54 min quando da realização da $3^{\mathrm{a}}$ simulação de precipitação, conforme demonstra resumidamente a Tabela 1 .

As informações da Tabela 1 evidenciam que o residual de água retido nos interstícios do solo aumentou o tempo para início da infiltração. Isto é evidente entre a $1^{\mathrm{a}}$ e $2^{\mathrm{a}}$ simulações, onde o intervalo de tempo entre elas não foi suficiente para secar o volume de solo contido no lisímetro; ou seja, com maior conteúdo inicial de água no solo, o tempo para coleta da $1^{\mathrm{a}}$ amostra de infiltração após o início 
Tabela 1. Medições do tempo para início da coleta de amostras de infiltração e de escoamento superficial

\begin{tabular}{cccc}
\hline Simulação & $\begin{array}{c}\text { Início da } \\
\text { Simulação } \\
\text { (início da chuva) }\end{array}$ & $\begin{array}{c}\text { Tempo para } \\
\text { a } 1^{\mathrm{a}} \text { coleta } \\
\text { de infiltração }\end{array}$ & $\begin{array}{c}\text { Tempo para a } \\
1^{\mathrm{a}} \text { coleta de escoa- } \\
\text { mento superficial }\end{array}$ \\
\hline $1^{\mathrm{a}}(08 / 07 / 10)$ & $9: 15 \mathrm{~h}$ & $0: 16 \mathrm{~h}$ & - \\
$2^{\mathrm{a}}(09 / 07 / 10)$ & $8: 29 \mathrm{~h}$ & $0: 29 \mathrm{~h}$ & - \\
$3^{\mathrm{a}}(09 / 07 / 10)$ & $16: 47 \mathrm{~h}$ & $0: 08 \mathrm{~h}$ & $1: 02 \mathrm{~h}$ \\
\hline
\end{tabular}

da simulação aumentou de 16 para 29 min, demonstrando que o solo mais úmido apresenta menor capacidade inicial de infiltração, devido à diminuição dos efeitos de capilaridade. ${ }^{22}$

Com relação ao escoamento superficial, foi necessário 1 h e 2 min para se superar a capacidade de infiltração do solo o que, sob uma intensidade pluviométrica constante de $115 \mathrm{~mm} \mathrm{~h}^{-1}$ sobre a área de 1 $\mathrm{m}^{2}$ do lisímetro, correspondeu ao volume de $118,83 \mathrm{~L}$ de precipitação.

\section{Concentrações de 2,4-D}

A variação das concentrações do herbicida 2,4-D durante a realização do experimento é apresentada na Tabela 2. De modo geral, pôde-se observar a dissipação (decaimento) do herbicida durante as três precipitações simuladas, com notório decréscimo das concentrações da $1^{\text {a }}$ para a $3^{\text {a }}$ simulação. Os valores medidos nas amostras apresentaram ordem de grandeza muito menor em relação à concentração inicial aplicada de 4,03 $\mathrm{g} \mathrm{L}^{-1}$ (concentração da calda).

Em termos das médias, para amostras obtidas de água infiltrada, os valores de concentração de 2,4-D encontrados foram de 3,34; 2,30 e $0,19 \mathrm{mg} \mathrm{L}^{-1}$ para a $1^{\mathrm{a}}, 2^{\mathrm{a}}$ e $3^{\mathrm{a}}$ simulações, respectivamente; ou seja, 0,$082 ; 0,057$ e $0,004 \%$, respectivamente, em relação à concentração inicial aplicada. Para o conjunto de amostras de escoamento superficial, obtidas somente na $3^{\mathrm{a}}$ simulação, a concentração média foi de $0,12 \mathrm{mg} \mathrm{L}^{-1}-0,003 \%$ em relação à concentração inicial.

\section{Balanço de massa do 2,4-D}

A Figura 2 mostra as cargas de 2,4-D medidas durante a realização do experimento, obtidas pelo produto entre a concentração na amostra, a vazão e o tempo de amostragem, sendo expressas em unidade de massa. Para a composição do balanço de massa (entradas x saídas) o lisímetro foi considerado o volume de controle; a entrada foi a aplicação inicial e única de 2,4-D realizada no dia 08/07/10 e as saídas foram as cargas de infiltração e escoamento superficial decorrentes das precipitações simuladas. Através das cargas acumuladas de infiltração e escoamento superficial foi possível fechar o balanço de massa. ${ }^{2}$

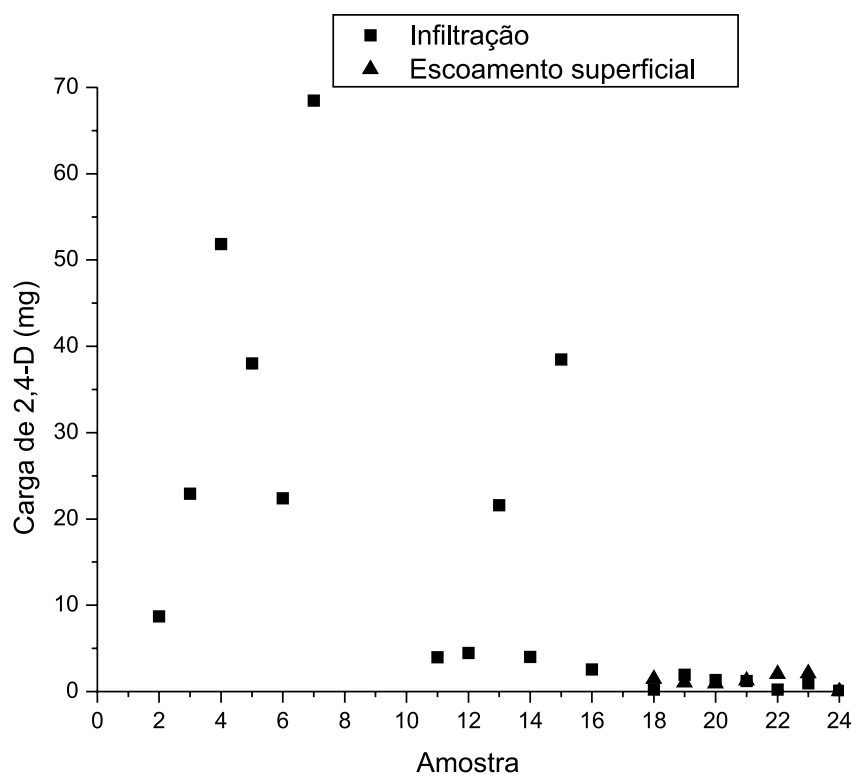

Figura 2. Cargas de 2,4-D obtidas por infiltração e escoamento superficial durante a realização do experimento em lisímetro

É possível notar um comportamento oscilatório para as cargas transportadas por infiltração nas três simulações, com picos mais notórios na $1^{\mathrm{a}}$ e $2^{\mathrm{a}}$ simulações, onde as cargas máximas foram de 68,48 e 38,48 mg, respectivamente. A oscilação com menor magnitude também foi percebida no transporte por escoamento superficial, onde a carga máxima foi de 2,09 mg no intervalo de $10 \mathrm{~min}$. A carga acumulada permite verificar o quanto foi transportado em relação à massa inicial de 1.007,5 mg do herbicida aplicado (Figura 3).

A Figura 3 mostra que ao final do experimento, 293,47 mg foram transportadas por infiltração e $8,77 \mathrm{mg}$ foram transportadas por escoamento superficial. Em termos percentuais, 29,12 e 0,87\% do total de 2,4-D aplicado foram dissipados para o ambiente por infiltração e escoamento superficial, respectivamente, totalizando 29,99\%

Tabela 2. Concentrações de 2,4-D detectadas em amostras de infiltração e escoamento superficial

\begin{tabular}{|c|c|c|c|c|}
\hline \multirow{2}{*}{$\begin{array}{l}\text { Tempo em relação ao início } \\
\text { da simulação de chuvas (min) }\end{array}$} & \multicolumn{4}{|c|}{ Concentração de 2,4-D $\left(\mathrm{mg} \mathrm{L}^{-1}\right)^{*}$} \\
\hline & $\begin{array}{l}1^{\text {a }} \text { Simulação } \\
\text { (infiltração) }\end{array}$ & $\begin{array}{l}2^{\text {a }} \text { Simulação } \\
\text { (infiltração) }\end{array}$ & $\begin{array}{l}3^{\text {a }} \text { Simulação } \\
\text { (infiltração) }\end{array}$ & $\begin{array}{c}3^{\text {a }} \text { Simulação } \\
\text { (escoamento superficial) }\end{array}$ \\
\hline 10 & - & - & $0,317 \pm 0,003$ & - \\
\hline 20 & $0,015 \pm 0,004$ & - & $0,384 \pm 0,004$ & - \\
\hline 30 & $1,886 \pm 0,002$ & $1,984 \pm 0,003$ & $0,209 \pm 0,003$ & - \\
\hline 40 & $3,223 \pm 0,002$ & $1,152 \pm 0,002$ & $0,234 \pm 0,005$ & - \\
\hline 50 & $4,855 \pm 0,005$ & $5,833 \pm 0,004$ & $0,032 \pm 0,002$ & - \\
\hline 60 & $4,936 \pm 0,002$ & $1,087 \pm 0,003$ & $0,139 \pm 0,003$ & $0,342 \pm 0,004$ \\
\hline 70 & $2,638 \pm 0,004$ & $5,392 \pm 0,006$ & $0,032 \pm 0,002$ & $0,076 \pm 0,005$ \\
\hline 80 & $8,172 \pm 0,002$ & $0,326 \pm 0,005$ & - & $0,062 \pm 0,005$ \\
\hline 90 & $2,641 \pm 0,002$ & $0,371 \pm 0,005$ & - & $0,074 \pm 0,003$ \\
\hline 100 & $4,295 \pm 0,003$ & - & - & $0,095 \pm 0,003$ \\
\hline 120 & $0,753 \pm 0,002$ & - & - & $0,091 \pm 0,003$ \\
\hline
\end{tabular}

* médias das amostras em triplicata \pm desvio padrão. 


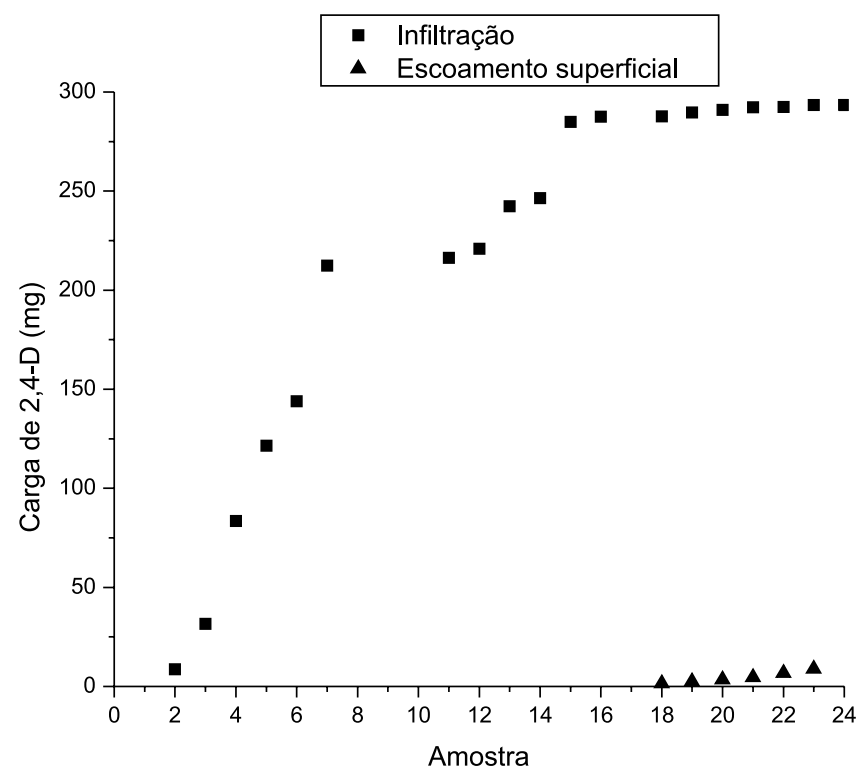

Figura 3. Cargas acumuladas de 2,4-D obtidas por infiltração e escoamento superficial durante a realização do experimento em lisímetro

transferidos para o ambiente. Conforme ilustra a Figura 4, 70\% da massa do pesticida não foram encontradas nos processos de infiltração e escoamento superficial. Especula-se que esse percentual majoritário pode ter participado de processos de transformação ou retenção. ${ }^{7,23}$

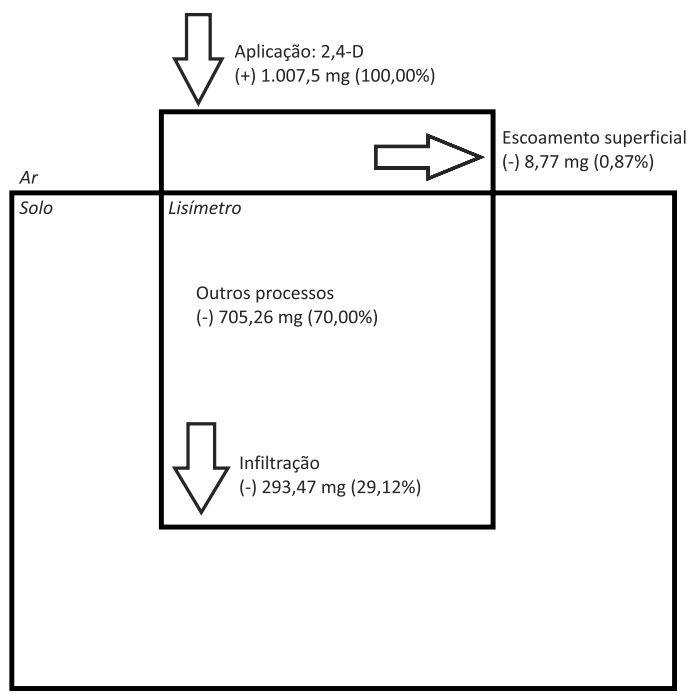

Figura 4. Balanço de massa para o 2,4-D no experimento em lisímetro

A hipótese de transformação biótica (biodegradação) deve ser considerada mesmo frente ao curto intervalo de tempo analisado por este experimento. A biodegradação do 2,4-D é considerada rápida e metade da dose aplicada pode ser degradada por microrganismos em até 10 dias. ${ }^{24} \mathrm{~A}$ retenção na fração orgânica do solo também deve ser considerada, mesmo frente aos baixos valores de constante de adsorção à matéria orgânica que o 2,4-D apresenta. ${ }^{7,8,25,26}$ Sabe-se que esse herbicida adsorve preferencialmente na fração orgânica do solo e que a adsorção, ainda que baixa se comparada a outros pesticidas, é maior em solos com maior teor de carbono orgânico e menor $\mathrm{pH} \cdot{ }^{7,25} \mathrm{~A}$ literatura cita como fraca a adsorção do 2,4-D na fase mineral do solo, especialmente nas argilas. ${ }^{7}$ Isso ocorre porque as cargas negativas dos coloides do solo repelem as moléculas do herbicida, também negativas quando este se encontra em solução aquosa. ${ }^{27}$
Analisando somente o transporte por infiltração, pôde-se notar que $21,07 \%$ da massa do 2,4-D já foi transportado logo na $1^{\text {a }}$ precipitação, $7,45 \%$ foi transportado na $2^{\mathrm{a}}$ e apenas $0,60 \%$ na última chuva simulada. Isso sugere ação do transporte preferencial e o forte efeito dissipador de chuvas que ocorrem logo após a aplicação do 2,4-D.

Num experimento semelhante, utilizando glifosato, ${ }^{2}$ resultados da mesma ordem de grandeza foram encontrados após a simulação de três chuvas. Em relação às cargas totais, o transporte por infiltração e escoamento superficial obtido para o 2,4-D foi de 29,12 e $0,87 \%$, respectivamente, enquanto que o experimento com glifosato encontrou 15,4 e 1,7\% para infiltração e escoamento superficial, respectivamente. ${ }^{2}$ Destaca-se que os experimentos apesar de apresentarem metodologias experimentais semelhantes e resultados de mesma ordem de grandeza, não são perfeitamente comparáveis, pois foram conduzidos em tipos de solo diferentes, com ingredientes ativos diferentes e metodologias analíticas também diferentes.

Em experimento com chuvas reais (não simuladas) sobre lisímetros, foram encontradas perdas máximas por lixiviação de $6 \%$ para o inseticida Carbofuran, valor bem menor que o encontrado com chuvas simuladas. ${ }^{15}$ Contudo, chuvas de variadas intensidades após a aplicação de agrotóxicos podem ocorrer e tais ocorrências implicam em riscos ao ambiente, além de prejuízos financeiros ao produtor rural.

A extrapolação dos resultados obtidos em lisímetros para áreas de bacias hidrográficas certamente forneceria estimativas superestimadas para o transporte dos ingredientes ativos estudados. A literatura apresenta estimativas de perdas por escoamento superficial em áreas agrícolas com valores na ordem de 0,001 a 1,0\% do total aplicado, além de perdas por infiltração da ordem de $5 \% .^{28}$

Em relação aos experimentos com agrotóxicos em lisímetros, cabe ainda destacar que embora as perdas em relação à carga aplicada tenham sido maiores no transporte por infiltração, o experimento realizado com glifosato, ${ }^{2}$ ao gerar três eventos de escoamento superficial e três de infiltração, mostrou que as concentrações maiores foram encontradas no transporte por escoamento superficial. Resultado semelhante foi obtido em pesquisa na Bacia do Rio Itajaí, revelando o importante papel atenuador do solo ao realizar uma filtragem para a manutenção da qualidade das águas subterrâneas. ${ }^{9}$

Outro fator relevante é a contribuição da vazão no arraste das moléculas dos herbicidas. Como as cargas foram calculadas pelo produto entre concentração, vazão e tempo de amostragem, é de se esperar que as vazões contribuam significativamente na quantidade de massa transportada. Isso ocorreu no experimento com o 2,4-D, ou seja, cargas maiores foram transportadas para águas subterrâneas porque as vazões de infiltração foram maiores que as de escoamento superficial.

\section{CONCLUSÕES}

A simulação de três chuvas sobre lisímetro gravimétrico após a aplicação de herbicida à base de 2,4-D permitiu a dissipação para o ambiente de 29,99\% da massa inicial aplicada. Por meio das cargas transportadas, mostrou-se que, sob a ação do transporte preferencial, grande parte da massa do 2,4-D foi dissipada já na $1^{\mathrm{a}}$ chuva simulada.

Do total de massa aplicado, 29,12\% foram dissipados por infiltração e $0,87 \%$ por escoamento superficial. Um percentual majoritário da massa do herbicida pode ter participado de processos de retenção ou transformação, tendo o solo como reservatório final. As hipóteses de transformação biótica (biodegradação) e de retenção na fração orgânica do solo devem ser consideradas, mesmo frente ao curto intervalo de tempo analisado neste experimento e aos baixos valores de constante de adsorção pela matéria orgânica que o 2,4-D apresenta se comparado a outros pesticidas.

Mostrou-se que, nas condições do experimento realizado, o 
transporte preferencial gerado por precipitações agiu no carreamento do herbicida 2,4-D, tanto por infiltração como por escoamento superficial.

\section{AGRADECIMENTOS}

Ao Prof. A. Pinheiro e ao colega V. Kaufmann pela parceria na realização do experimento em lisímetro. Ao Prof. C. Fernandes pela ajuda na discussão dos resultados.

\section{REFERÊNCIAS}

1. www.andef.com.br/home, acessada em Janeiro 2012.

2. Queiroz, G. M. P.; Silva, M. R.; Bianco, R. J. F.; Pinheiro, A.; Kaufmann, V.; Quim. Nova 2011, 34, 190.

3. http://www.ibama.gov.br/phocadownload/Qualidade_Ambiental/ produtos_agrotoxicos_comercializados_brasil_2009.pdf, acessada em Janeiro 2012.

4. http://msdssearch.dow.com/PublishedLiteratureDAS/ dh_058c/0901b8038058c62a.pdf?filepath=br/pdfs/noreg/013-05107. pdf\&fromPage=GetDoc, acessada em Janeiro 2012 .

5. http://portal.anvisa.gov.br/wps/wcm/connect/bdea3b804745780e857bd 53fbc4c6735/D27++24-D.pdf?MOD=AJPERES\&useDefaultText=0\&u seDefaultDesc $=0$, acessada em Janeiro 2012.

6. Kamrin, M. A.; Pesticide profiles - toxicity, environmental impact and fate, CRC Press LLC: Michigan, 1997.

7. Vieira, E. M.; Prado, A. G. S.; Landgraf, M. D.; Rezende, M. O. O.; Quim. Nova 1999, 22, 305.

8. Pinheiro, A.; Moraes, J. C. S.; Silva, M. R.; Revista Brasileira de Engenharia Agrícola e Ambiental 2011, 15, 533.

9. Pinheiro, A.; Silva M.; Kraisch, R.; Revista de Gestão de Água da América Latina 2010, 7, 17.

10. Tomlin, C.; The Pesticide Manual: Incorporating the Agrochemicals Handbook, 10 ${ }^{\text {th }}$ ed., British Crop Protection Council: Surrey, 1994.
11. Garcia, C. S.; Dissertação de Mestrado, Universidade Federal do Paraná, Brasil, 2005.

12. http://www.lysimeter.at, acessada em Julho 2011

13. Matallo, M. B.; Luchini, L. C.; Gomes, M. A. F.; Spadotto, C. A.; Cerdeira, A. L.; Marin, G. C.; Pesticidas: Revista de Ecotoxicologia e Meio Ambiente 2003, 13, 83.

14. Castro, N. R. A.; Rigitano, R. L. O.; Lima, J. M.; Guerreiro, M. C.; Cienc. Agrotecnol. 2008, 32, 1818.

15. Martins, E. L.; Weber, O. L. S.; Dores, E. G. C.; Spadotto, C. A.; Barbosa, I. A.; XLVI Congresso Brasileiro de Química, Salvador, Brasil, 2006.

16. http://mapas.ibge.gov.br/solos/viewer.htm, acessada em Abril 2011.

17. http://www.iapar.br/modules/conteudo/conteudo.php?conteudo=595, acessada em Maio 2012.

18. Empresa Brasileira de Pesquisa Agropecuária; Manual de Métodos de Análise de Solo, $2^{\text {a }}$ ed., CNPS: Rio de Janeiro, 1997.

19. Nelson, D. W.; Sommers, L. E. Em Methods of Soil Analysis - Chemical and Microbiological Properties; Page, A. L.; Miller, R. H.; Keeney, D. R., eds.; Soil Science Society of America: Madison, 1982, chap. 29.

20. Segnini, A.; Santos, L. M.; Silva, W. T. L.; Quim. Nova 2008, 31, 94.

21. Amarante Jr, O. P.; Brito, N. M.; Santos, T. C. R.; Nunes, G. S.; Ribeiro, M. L.; Talanta 2003, 60, 115.

22. Spohr, R. B.; Carlesso, R.; Gallárreta, C. G.; Préchac, F. G.; Petillo, M. G.; Cienc. Rural 2009, 39, 74.

23. Prata, F.; Tese de Doutorado, Universidade de São Paulo, Brasil, 2002.

24. Boivin, A.; Amellal, S.; Schiavon M.; Genuchten, M. T.; Environ. Pollut. $\mathbf{2 0 0 5}, 138,92$.

25. Ismail, B. S.; Sameni, M.; Halimah, M.; Asian J. Agric. Res. 2009, 3, 67.

26. http://water.epa.gov/drink/contaminants/basicinformation/2-4-d-2-4-dichlorophenoxyacetic-acid.cfm, acessada em Junho 2011.

27. Grover, R.; Smith, A. E.; Can. J. Soil Sci. 1974, 54, 179.

28. http://www.cnpma.embrapa.br/download/documentos_58.pdf, acessada em Janeiro 2012. 